\title{
Uma Alemanha brasileira: a denominação dos lugares no complexo colonial da Colonizadora Meyer*
}

Rosane Marcia Neumann ${ }^{1}$

\section{Resumo}

O artigo discute os interesses presentes na escolha dos nomes para a denominação dos lugares no complexo colonial da Empresa de Colonização Dr. Herrmann Meyer, situado no Planalto Rio-Grandense, fundado em 1898, pelo empresário alemão Dr. Herrmann Meyer. A Colonizadora tinha por objetivo nominar as colônias, as linhas coloniais e as ruas da sede urbana com nomes que remetessem à Alemanha, o que foi parcialmente implantado na colônia Neu-Württemberg. Todavia, esse propósito concorria com a prática local, que concedia aos agrimensores a preferência de denominar os lugares por eles demarcados, e com as referências cotidianas já de uso corrente.

Palavras-chave: Colonizadora Meyer. Colônia Neu-Württemberg. Denominação dos lugares.

\begin{abstract}
The article discusses the interests present in the choice of names for the denomination of places in the colonial complex of Company of Colonization Dr. Herrmann Meyer, located in the Plateau Rio-grandense, founded in 1898 by German entrepreneur Dr. Herrmann Meyer. The Company of Colonization aimed to nominate the colonies, colonial lines and the streets of the urban centers with names remetessem to Germany, which was partially implemented in Neu-Württemberg colony. However, this purpose competed with local practice, which granted the land surveyors preference to name the places they demarcated, and with everyday references already in common use.
\end{abstract}

Keywords: Colonizadora Meyer. Neu-Württemberg Colony. Denomination of places.

\footnotetext{
* Uma discussão ampliada da temática encontra-se na tese de doutorado de NEUMANN (2009).

${ }^{1}$ Doutora em História. Professora do Programa de Pós-Graduação em História da Universidade de Passo Fundo. rosaneneumann@upf.br
} 


\section{Introdução}

A imigração "[...] representa uma longa viagem. E viagens, na precisa expressão de Leed (1992, p. 14-15), têm três diferentes momentos, cuja duração varia: há sempre uma partida, um trânsito e uma chegada" (apud CONSTANTINO, 2007, p. 395). Todavia, esse deslocamento no espaço influencia os indivíduos, configura grupos sociais e modifica estruturas, tanto no ponto de partida quanto no ponto de chegada. Sonhos, expectativas, ambições, embarca(va)m junto nessa viagem. O (e)imigrante deixa de existir em um espaço e passa a existir em outro, pois

o momento de viagem dos imigrantes pode ser comparado com a transferência de um mundo para outro. Naquela época, em que o emigrante raramente tinha possibilidade de voltar, a emigração era um tipo de morte simbólica, transplante de sua alma. Ele 'morria' no lugar onde vivera toda a vida anterior, para as pessoas que deixara para sempre, e 'nascia' no lugar novo (BYTSENKO, 2006, p. 102).

No momento da chegada, o imigrante imaginava encontrar a nova Heimat com uma infraestrutura semelhante àquela deixada em sua aldeia natal: um pequeno povoado central, cercado pelos campos de cultivo ${ }^{2}$. Transposto para o projeto de colonização do empresário alemão Herrmann Meyer, via empresa de colonização, situada em Cruz Alta e Palmeira das Missões, região do Planalto Rio-Grandense, que se propunha a formar uma colônia étnica, onde os imigrantes realmente pudessem permanecer alemães, isso estava mais presente - Neu-Württemberg como a Alemanha brasileira, e o seu proprietário, um compatriota.

Projetos semelhantes estavam sendo implantados em outras regiões do país, como, por exemplo, a construção do mito de Nova Friburgo como a Suiça brasileira, no período de 1910 a 1960. João Raimundo de Araújo (2003) concebe o “Mito da Suíça brasileira" como uma construção ideológica, datada no âmago do processo industrial vivido por Nova Friburgo, a partir dos investimentos efetuados por empresários de nacionalidade alemã, iniciados em 1911, no setor têxtil. Segundo o autor, a identificação de Nova Friburgo com a Suíça era mais interessante: um país neutro na guerra, adiantado, civilizado, moderno, branco e europeu. No reverso, mostra uma cidade pobre, com os seus tipos populares. Uma classe operária explorada e pouco organizada, manifestações operárias isoladas, em prol de melhorias salariais; o surgimento dos primeiros sindicatos, mediados pelo "peleguismo". Ao mesmo tempo, as festas da cidade cumpriam os objetivos de mostrar a força da indústria, da lavoura e do comércio, enaltecer o passado suíço, fortalecer a ligação da população com a Igreja Católica e, sobretudo, afirmar a identidade friburguense pela sua diferença em relação às demais cidades do Brasil. Tinha um passado calcado num povo europeu, era moderna, industrializada. "O discurso do mito fundador e a realidade, no caso de Nova Friburgo, combinaram-se para consoli-

\footnotetext{
${ }^{2}$ Günter Weimer (2005, p. 37) afirma que o termo aldeia possui um sentido ambíguo, pois "por um lado, significa pequeno aglomerado urbano onde moravam os agricultores. Por outro, significa o conjunto de terras agrícolas, pastagens e florestas sob jurisdição do conglomerado urbano". A estrutura de uma aldeia e o formato dos seus campos adjacentes variavam de uma região alemã para a outra.
} 
dar um projeto de cidade capitalista industrial" (ARAÚJO, 2003, p. 281).

Desse modo, a organização geral do complexo colonial da Empresa de Colonização Dr. Herrmann Meyer seguiu o mesmo padrão adotado nas demais colônias oficiais e privadas instaladas no Rio Grande do Sul, no decorrer do século XIX e início do século XX, com os devidos ajustes. Predominou como forma de organização social a denominada picada. Martin Dreher (2005) explica que essa designação também pode ser substituída, regionalmente, por linha, lajeado, travessa ou travessão. Na literatura, ainda é possível encontrar a designação alemã Schneise ou a forma alemanizada Pikade. A picada consistiu na forma básica de penetração na floresta subtropical, com a abertura de pequenas trilhas, ao longo das quais foram sendo instalados os imigrantes e seus descendentes nos seus respectivos lotes coloniais, os quais se limitavam, em uma extremidade, com a estrada, e, na outra, com o lote oposto, divididos geralmente por um rio. A picada, que inicialmente nada mais era do que trilha de acesso a uma propriedade, passou a ser, em pouco tempo, orientadora e organizadora de vida comunal, geograficamente identificável, concentrando escola, igreja, casa comercial, profissionais de ofício. Na região do Planalto Rio-Grandense predominou a designação linha.

Em seu respectivo lote colonial, o colono estabelecia a sede de sua propriedade agrícola, o seu Hof Weimer (2005, p. 29) explica que o Hof "compõe-se da residência, das benfeitorias, da horta, do pomar e do pátio, que, dentro da aldeia, definiam a posse da unidade familiar". Nas colônias rio-grandenses, esse termo permaneceu em uso, embora adaptado ao novo contexto, pois "na Alemanha o Hof era, primordialmente, aldeão, aqui passou a ser rural" (WEIMER, 2005, p. 29)3.

Como não foi possível compor um único complexo colonial, formaram-se dois núcleos centrais, Xingu (fundado em 1897) e Neu-Württemberg (1898), atuais municípios de Novo Xingu e Panambi/Condor. As plantas baixas dessas duas colônias dão a ver um espaço previamente planejado, dividido por linhas coloniais, com lotes regulares, ordenados, devidamente numerados, permitindo uma localização rápida. Ao mesmo tempo, para a colônia Neu-Württemberg, havia sido delimitada uma área para a instalação do Stadtplatz, ou sede urbana, com suas quadras, terrenos e ruas, cercada por um conjunto de áreas menores denominadas chácaras, e os lotes coloniais propriamente ditos.

O ideal de colônia alemã em toda sua plenitude, na prática, foi adaptado às condições permitidas pelo meio, bem como reinterpretado pelos administradores da Colonizadora Meyer, diretor de colônia, agrimensor, advogado, colonos, imigrantes, formando uma colônia com características próprias, singular. Era prática comum, pelo menos no Rio Grande do Sul, a preferência dada aos agrimensores de denominarem os lugares por eles demarcados, incluindo a área como um todo e os rios, utilizando-se de pontos de referência que, futuramente, facilitassem a identificação do local. Essa prática permitiu que colônias, linhas coloniais e ruas ostentassem nomes tipicamente brasileiros, contrariando as expectativas do colonizador, razão também das queixas do diretor da empresa, Horst Hoffmann:

\footnotetext{
${ }^{3}$ Weimer (2005) traduziu Hof por sítio, considerando que não há uma tradução literal que dê conta desse termo. No senso comum, é traduzido e entendido como pátio.
} 
[...] relativo aos nomes das linhas, eu sou bem do seu ponto de vista e lamento que nós temos nomes como 7 de Setembro, 15 de Novembro, etc. em Neu-Württemberg. É a parte mais antiga demarcada por Silvestre [Manoel da Silva]. O nome da área medida pelo Dr. Ahrons (terra dos Mello), para Xingu e o Stadtplatz eu mesmo escolhi, contra isso eu antecipei o Dr. Ahrons na medição da linha no Rincão, como também as ruas no Stadtplatz, porque aqui o dar os nomes é um direito primeiro do agrimensor. Mas eu em todos esses casos vou saber colocar seu [Meyer] desejo em primeiro lugar ${ }^{4}$.

Nessa disputa pela denominação dos lugares, sobressaía outro aspecto: a região colonial formada em Cruz Alta e Palmeira já estava povoada há várias décadas, e a população, para sua localização e comunicação cotidiana, havia nomeado os lugares. Assim, no momento da entrada da Colonizadora Meyer na área, a renomeação acabou se constituindo um ato meramente formal, permanecendo em uso o antigo nome. Por exemplo, na linha Leipzig, no momento da medição, os arroios até então identificados simplesmente como sanga, receberam nomes como Carlos Dhein, Dr. Horst Hoffmann, ou tiveram seus nomes trocados, como o Arroio dos Veados, que passou a Arroio Dr. Herrmann Meyer, mas apenas formalmente, visto que, no uso diário, permaneceram as antigas referências, ou, em alguns casos, ambas se perderam. O mesmo ocorria com os nomes alemães, pois o Stadtplatz Elsenau, no cotidiano, era apenas Stadtplatz da colônia Neu-Württemberg, caindo o nome Elsenau em desuso, já na década de 1910. Na própria correspondência da direção da Colonizadora, o nome Elsenau não era usado, sendo comum apenas na correspondência do pastor Faulhaber, enquanto ocupava tal função. Afinal, na questão nominal dos lugares, é difícil

impor regras, local onde certas práticas e costumes devem acontecer, pois não cedem a decretos oficiais de prefeitos e governantes. No imaginário popular e nas relações cotidianas, permanecem as antigas denominações, ou convivem nomes oficiais com nomes dados pelos populares conforme o uso que faziam do local (SOUSA, 2001, p. 82).

Para Michel de Certeau (2007, p. 184-185), os nomes hierarquizam e denominam semanticamente os lugares e, dessa forma, acabam ligados também a essa funcionalidade. Essas palavras "perdem aos poucos o seu valor gravado, como moedas gastas, mas a sua capacidade de significar sobrevive à sua determinação primeira". Assim,

nesses núcleos simbolizadores se esboçam (e talvez se fundam) três funcionamentos distintos (mas conjugados) das relações entre práticas espaciais e práticas significantes: 'o crível, o memorável e o primitivo'. Designam aquilo que 'autoriza' ou (faz possíveis ou críveis) as apropriações espaciais, aquilo que ali se repete (ou se recorda) de uma memória silenciosa e fechada, e aquilo que aí se acha estruturado e não cessa de ser marcado por uma origem infantil (in-fans).

E continua o autor:

\footnotetext{
${ }^{4}$ Relatório 5-7. De $1 / 3$ a 15/4/1903. Porto Alegre, 25/4/1903 (cont.). Horst Hoffmann a Herrmann Meyer, Leipzig. Pasta Transcrição Livro Copiativo 44, Caixa 109, MAHP (Museu e Arquivo Histórico Professor Hermann Wegermann, Panambi).
} 
Esses três dispositivos simbólicos organizam os 'topoi' dos discursos sobre/da cidade (a legenda, a lembrança e o sonho) de uma maneira que escapa também à sistematicidade urbanística. Pode-se reconhecê-los já nas funções dos nomes próprios: eles tornam habitável ou crível o lugar que vestem com uma palavra (esvaziando-se do seu poder classificador, adquirem o de 'permitir' outra coisa): lembram ou evocam os fantasmas (mortos supostamente desaparecidos) que ainda perambulam, escondidos nos gestos e nos corpos que caminham; e, enquanto nomeiam, isto é, impõem uma injunção vinda do outro (uma história) e alteram a identidade funcionalista afastando-se dela, criam no próprio lugar essa erosão ou não-lugar aí cavado pela lei do outro (CERTEAU, 2007, p. 185-186).

A colônia Xingu teve seu nome atribuído por Carlos Dhein, em 1897, como uma reverência ao Xingu mato-grossense, destino da primeira expedição de Meyer, recémconcluída ${ }^{5}$. Logo, não atendia aos propósitos de Meyer, pois em nada lembrava a Alemanha, por consequência, pouco chamativo, e muitas vezes, identificado como terra indígena. Nessa colônia, também não foi instalada uma sede urbana. Em virtude da localização da área, os lotes coloniais formaram longas e estreitas faixas retangulares, ao contrário do projeto inicial de seguir o modelo europeu de lotes com formato de quadrado. O formato dos lotes coloniais surpreendeu Meyer: "a justificativa de que os colonos velhos preferem as colônias retangulares/estreitas às mais quadradas/alargadas me surpreendeu. Eu até agora sempre tive uma opinião contrária, [...] isso dá uma impressão estranha, e gera perguntas curiosas aqui" ${ }^{\prime \prime}$. O nome das linhas coloniais também não atendeu ao princípio imaginado: Linha Dr. Meyer (43 lotes), Linha Nonohay (27 lotes) e Linha Palmeira (14 lotes) - respectivamente, uma homenagem ao colonizador, ao distrito e ao município, nesse caso, referências locais/ nacionais ${ }^{7}$.

Já Neu-Württemberg, por si só, indicava tratar-se de uma colônia alemã, como uma possibilidade para a construção de uma nova Württemberg no Brasil. Os nomes dos lugares na colônia procuravam reconfigurar simbolicamente a Alemanha deixada para trás. Assim, na denominação das linhas coloniais, o imigrante ou descendente identificava as cidades ou regiões alemãs de origem: Leipzig, Stuttgart e Berlin, as quais formaram o núcleo inicial. Somaram-se a elas München, Hunsrück, Rheinland, Hindenburg e Schwaben. Paralelamente, encontravam-se as designações de linhas em reverência a fatos e lugares brasileiros: Rio Grande, Brasil, 7 de Setembro, 15 de Novembro; ou ligados à denominação anterior do lugar ou pontos de referência: Palmeira Sul; Rincão; Fiúza; Serrana; Caxambu; Inhame; ou ainda ao sobrenome do vendedor: Malheiros, Posse Magdalena (ou Magdalenenland), Posse Cordeiro, Fagundes; ou ainda aleatória, como

\footnotetext{
${ }^{5}$ Carlos Dhein foi sócio-fundador da Colonizadora Meyer e procurador de Meyer de 1897 a 1900, quando a sociedade foi dissolvida. Também foi o guia da expedição de Meyer à região do Xingu, no Mato Grosso, em 1896/1897 (cf. NEUMANN, 2009).

${ }^{6}$ Carta. Leipzig, 16/6/1903. Herrmann Meyer a Horst Hoffmann, Porto Alegre. Pasta Cartas - Herrmann Meyer a Horst Hoffmann, Caixa 42, MAHP.

${ }^{7}$ A colônia Xingu pertenceu inicialmente ao território de Palmeira das Missões. Localizava-se no distrito de Nonoai. Contudo, com a redefinição dos limites entre esse município e Passo Fundo, por vários momentos, passou, juridicamente, a integrar o território do último. O limite oficial geralmente aceito entre os dois municípios era o rio da Várzea. Em 1939, desmembrou-se de Passo Fundo o novo município de Sarandi, incluindo em sua área o distrito de Xingu. Já em 1959, com a emancipação de Constantina, passou a distrito deste. Em 1996, o distrito de Xingu emancipou-se sob a denominação de Novo Xingu.
} 
Italiana. Neste último caso, nota-se que tanto na colônia Neu-Württemberg quanto na colônia Fortaleza/Erval Seco, havia uma linha Italiana, talvez com o objetivo de delimitar nominalmente esse espaço para os possíveis colonos italianos, ou pela grande quantidade de imigrantes italianos no país, ou, ainda, reproduzir a vizinhança europeia entre Alemanha e Itália.

Como a colônia se localizava nas margens do rio Palmeira, o qual dava o limite entre os municípios de Cruz Alta e Palmeira, ela se expandiu nas duas margens do rio. Na parte de Neu-Württemberg-Palmeira, formaram-se as linhas Herrmann, Alfred, Clara, em homenagem, respectivamente, a Meyer e ao casal Bornmüller, diretores da colônia entre 1904 e 1907; ligados à denominação anterior do lugar ou dos rios das proximidades, Divisa, Palmeira, Raiz, Pinhal; ou em relação à Alemanha ou nomes alemães: Emden, Zeppelin, Weddigen, Siegfried, Roland. Já a sede denominava-se Sete de Setembro e, posteriormente, Liberdade, situada no limite norte entre as linhas Raiz e Alfred ${ }^{8}$.

A área da colônia destinada para a sede, ou o Stadtplatz Elsenau, como foi nomeada em homenagem a Else Meyer, com as suas colinas, foi descrita em vários relatos como uma "pequena cidadezinha Turíngia", ou uma "pequena aldeia alemã". Concentrava o maior número de casas, além de pequenas oficinas, casas comerciais, bares, escola, igreja e uma área destinada para praça-central. A sede urbana foi previamente planejada como um espaço moderno e interligado com as linhas coloniais e as estradas principais, facilitando a circulação. Além do Stadtplatz central, foi planejado mais o Stadtplatz Sanga do Meio, como secundário, na linha Hindenburg, no extremo oeste da colônia, próximo ao rio ljuí.

Conforme as orientações de Meyer (1899), uma sede colonial não se comparava a uma cidade europeia, tendo em vista a sua simplicidade e sua área reduzida, mas, lançadas as bases, no futuro, transformar-se-ia em uma cidade - "a cidade é o produto do crescimento e não da criação instantânea" (WIRTH, 1979, p. 91) ${ }^{9}$. Os resquícios da estrutura de uma aldeia - entendendo-a como um pequeno aglomerado de casas, cercado pelos campos - são visíveis na sede da colônia e, em escala reduzida, nas linhas coloniais - para cada conjunto de lotes coloniais foi reservado um para a instalação de uma escola, igreja, cemitério, concentrando-se nas imediações os pequenos profissionais de ofício, casa comercial, salão de baile, etc. No restante das linhas coloniais, a

\footnotetext{
${ }^{8}$ Com a Campanha de Nacionalização levada a efeito pelo governo de Getúlio Vargas, ao longo do Estado Novo, os nomes das linhas coloniais foram "abrasileirados", bem como o próprio nome da colônia. Neu-Württemberg, na parte de Palmeira, foi alterado de Vila Liberdade para Condor. As novas denominações das linhas coloniais, modificadas em 1942, por ato do prefeito Pacífico Dias da Fonseca, foram Linha Stuttgart, passou à Ibagoby, que significa Céu Azul; Linha Leipzig passou a Iriapira, que significa Princípio de Rio; Linha Hindenburg passou a Assis Brasil; Linha Inhame passou a Maraney, que significa Saudade, Bondade, Inocência; Linha München passou à Morengaba, que significa Beleza; Linha Rheinland passou à Jacicema, que significa Esplendor da Lua; Linha Hunsrück passou a Ocearu, que significa Fartura; Linha Berlim passou a Timbará, que significa Plantador (Diário Serrano, 21/8/1943, n. 143, p. 4).

${ }^{9}$ Conforme Max Weber (1979, p. 74-77), a cidade não consiste apenas em um aglomerado de casas, mas também "uma associação econômica com propriedade territorial própria, com economia de receitas e despesas". Já no sentido político-administrativo, "a noção de cidade pode corresponder a uma localidade que economicamente não poderia pretender tal título. [...]. A passagem de uma 'cidade agrária' desse tipo para uma cidade de consumidores, produtores ou comerciantes é naturalmente muito fluída".
} 
distribuição das casas acompanhava o traçado das estradas e a própria distribuição dos lotes coloniais, concentrando-se ao longo de uma linha retilínea e, por consequência, uma distante da outra.

Seguindo o mesmo modelo das linhas coloniais, a escolha dos nomes para as ruas ou Strassen, no Stadtplatz Elsenau, deveria ser criteriosa e representativa. Como resultado, misturavam-se nomes de personagens históricos com pontos de referência utilitários, incorporados no cotidiano dos habitantes. Logo, era comum referir-se à rua da praça, do moinho, do açude, da escola ou do caminho das chácaras; ou de grandes personalidades da Alemanha, como Bismarck e Wilhelm; ou imigrantes alemães proeminentes no Rio Grande do Sul, como Koseritz (Quadro 1).

\section{Quadro 1 - Denominação das ruas na colônia Neu-Württemberg}

\begin{tabular}{|l|l|l|}
\hline \multicolumn{1}{|c|}{ Neu-Württemberg } & \multicolumn{1}{c|}{ Tradução } & \multicolumn{1}{c|}{ Panambi-hoje (Rua) } \\
\hline Marktplatz & Rua do Mercado/Praça & Hermann Faulhaber \\
\hline Bismarckstrasse & Rua Bismarck & 7 de Setembro \\
\hline Blücherstrasse & Rua Blücher & Jacob Bock \\
\hline Koseritzstrasse & Rua Koseritz & 10 de Novembro/ Bento Gonçalves \\
\hline Schillerstrasse & Rua Schiller & General Osório \\
\hline Schulstrasse & Rua da Escola & Alfredo Brenner/ Carlos Ernesto Knorr \\
\hline Wilhelmstrasse & Rua Guilherme & Daltro Filho \\
\hline Teichstrasse & Rua do Açude & Gaspar Martins \\
\hline Ludwigstrasse & Rua Luís & Benjamim Constant \\
\hline Chacaraweg & Caminho das Chácaras & Otto Kepler \\
\hline Herrmannstrasse & Rua Germano & Barão do Rio Branco \\
\hline Minolystrasse & Rua Minoly & $1^{\circ}$ de Maio \\
\hline Zeppelinstrasse & Rua Zeppelin & Duque de Caxias \\
\hline Karlstrasse & Rua Carlos & Herrmann Meyer \\
\hline Mühlstrasse & Rua do Moinho & Josino Lima \\
\hline Auguststrasse & Rua Augusto & Holanda/ Andrade Neves \\
\hline
\end{tabular}

Fonte: elaborado pela autora (2008).

Note-se que predominaram as referências relacionadas a lugares e pessoas, as quais, do mesmo modo que passaram a identificar uma pequena rua, desapareceram, quando não davam mais conta das mudanças ocorridas, esvaziando-se de seu significado. Saliente-se ainda que, como colônia privada, a Colonizadora Meyer possuía plenos poderes para nomear os lugares, além de determinar o planejamento urbano, incluindo a ampliação da área urbana e a abertura de novas ruas.

Concluída essa fase de instalação e comercialização dos terrenos urbanos, essa área passou a ser responsabilidade da municipalidade de Cruz Alta, já no final da década de 1920. Na década seguinte, como resultado da política nacionalista do governo Vargas, as ruas foram renomeadas, prevalecendo nomes de importantes políticos, militares 
e datas nacionais, e, em minoria, pessoas relacionadas à política de Cruz Alta - Josino Lima e Alfredo Brenner - e à própria colônia - Herrmann Meyer e Hermann Faulhaber; o colono Jacob Bock e os industrialistas Otto Kepler e Carlos Ernesto Knorr. Nesse momento, as referências que até então haviam servido para a orientação simples e prática da população, passaram a constituir um campo de disputas pelo poder simbólico.

Observando a planta do Stadtplatz Elsenau, elaborada em 1901 (Figura 1, inserida na próxima página) por Alexandre Ahrons, do Escritório Ahrons, de Porto Alegre, e a planta efetiva, adotada em 1904, notam-se várias modificações.

A planta como um todo apresentava um formato retangular, limitada ao sul e oeste pelo rio Fiúza, e, ao oeste e norte, pelo arroio do Engenho ou Moinho, com cinco ruas paralelas cortando a sede no sentido norte-sul, e estas, por sua vez, por ruas transversais. Sobressai ainda a regularidade das quadras (53) e terrenos (aproximadamente 625 , de perímetro variado, de 25 a 50 metros de frente, por 50 a 75 metros de lado), formando um conjunto equilibrado e ordenado. Na parte sul, o local para a ponte sobre o rio Fiúza e uma pequena praça, o Brücken-Platz, e, na parte mais a leste ainda, a área reservada para o cemitério. Aproximadamente no centro da sede, na quadra 27, havia um terreno reservado para a igreja, com uma praça, o Kirchen-Platz. Já ao norte da sede, em frente à Casa do Imigrante, a Praça do Mercado ou Markt-Platz. Como limite da sede, o açude do moinho e, a oeste deste, as benfeitorias da administração. Ao leste ainda indicava as colônias, diretamente a Linha Berlin, a qual acabou sendo transformada em chácara posteriormente, e a noroeste, a Linha Italiana. As áreas indicadas como terras do Estado foram incorporadas sucessivamente à colônia.

Quanto à denominação original das ruas, prestava-se homenagem àqueles diretamente envolvidos com a colonização, vinculados à Colonizadora, ou colonos residentes no local. Assim, foram planejadas as ruas paralelas: Horst-Strasse (Horst Hoffmann), Herrmann-Strasse (Herrmann Meyer), Mühlen-Strasse, Rudolf-Strasse (Rudolf Scharf) e Wasser-Strasse. Bem como ruas transversais: Karl-Strasse (Karl Wagner), Luiz-Strasse (Luiz Zügel ou Ludwig), August-Strasse, Elisabeth-Strasse (Elisabeth Meyer), Becker-Strasse, Kirchen-Strasse, Wilhelm-Strasse, Friedrich-Strasse, Berliner-Strasse, e Brücken-Strasse.

Conforme Horst Hoffmann, essa planta do Stadtplatz Elsenau, de 1901, e já distribuída para fins de propaganda por Herrmann Meyer, existia "apenas no papel", tendo em vista que as ruas ainda não haviam sido abertas, e mostrava-se em parte inviável, pois se tratava de uma sede ideal, mas não possível em toda sua extensão local, em decorrência do terreno acidentado. ${ }^{10}$ Posteriormente, adaptando a planta à realidade, as ruas retilíneas cederam lugar a ruas oblíquas e curvas, sendo incluídas algumas e excluídas outras. A área como um todo também foi reduzida pelo lado sul, bem como as três praças resultaram em apenas uma, e o cemitério passou da parte sul para a parte norte da sede, ao lado da capela Batista.

\footnotetext{
${ }^{10}$ Relatório 6. De 16 a 31/3/1902. Porto Alegre, 3/4/1902. Horst Hoffmann a Herrmann Meyer, Leipzig. Pasta Transcrição Livro Copiativo 44, Caixa 109, MAHP.
} 
Figura 1 - Planta Stadtplatz Elsenau, 1901

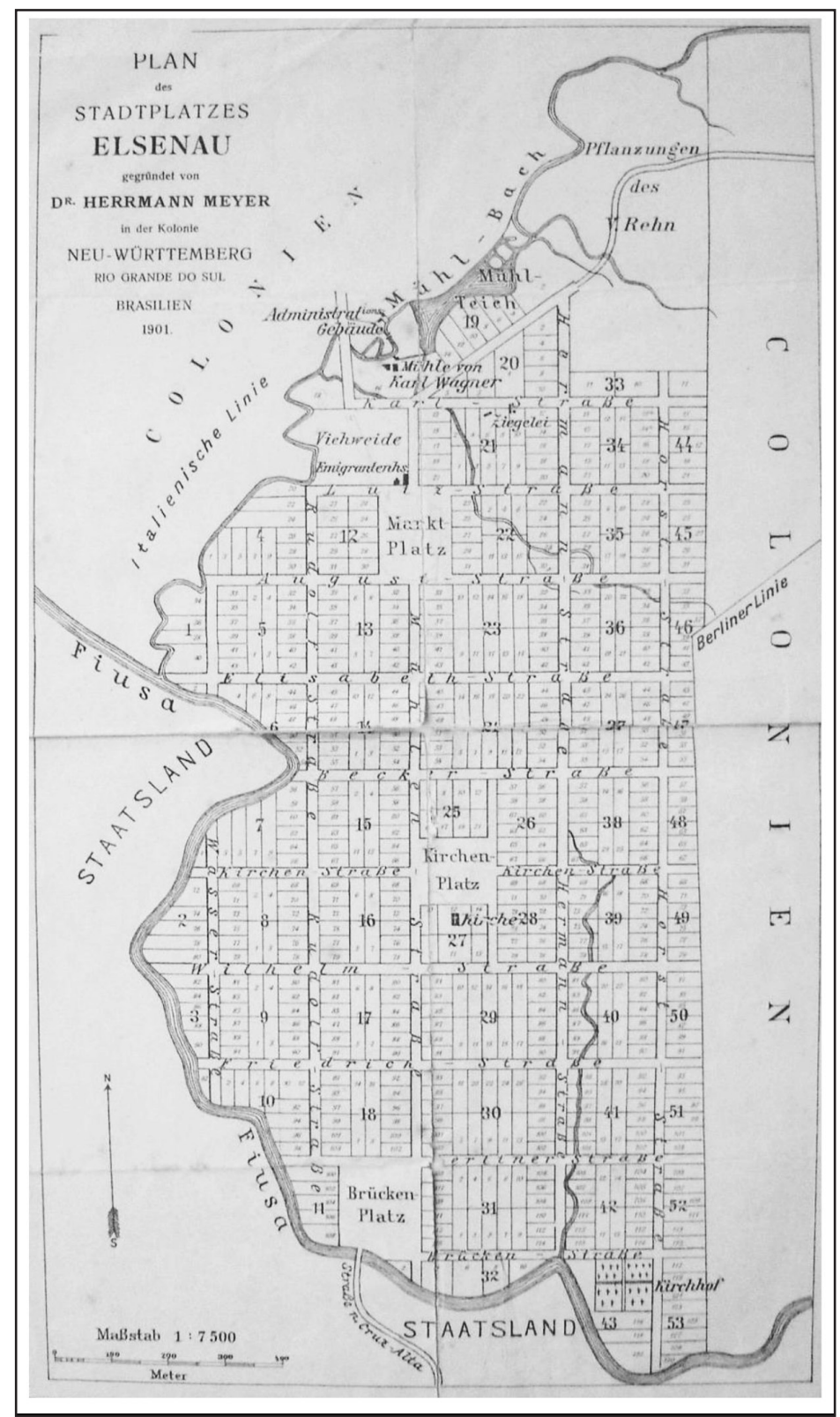

Fonte: Pasta Títulos de Legitimação de Posses de Terras, Caixa 27, MAHP. 
O diretor da colônia, Alfred Bornmüller, coordenou a elaboração da nova planta, em 1905/1906, com a redivisão da área leste em chácaras (Figura 2), ${ }^{11}$ e o diretor Hermann Faulhaber foi o responsável pelo traçado da ampliação da sede urbana e das ruas, no início da década de 1910 (Figura 3, inserida na próxima página).

Figura 2 - Planta Stadtplatz Elsenau, 1906

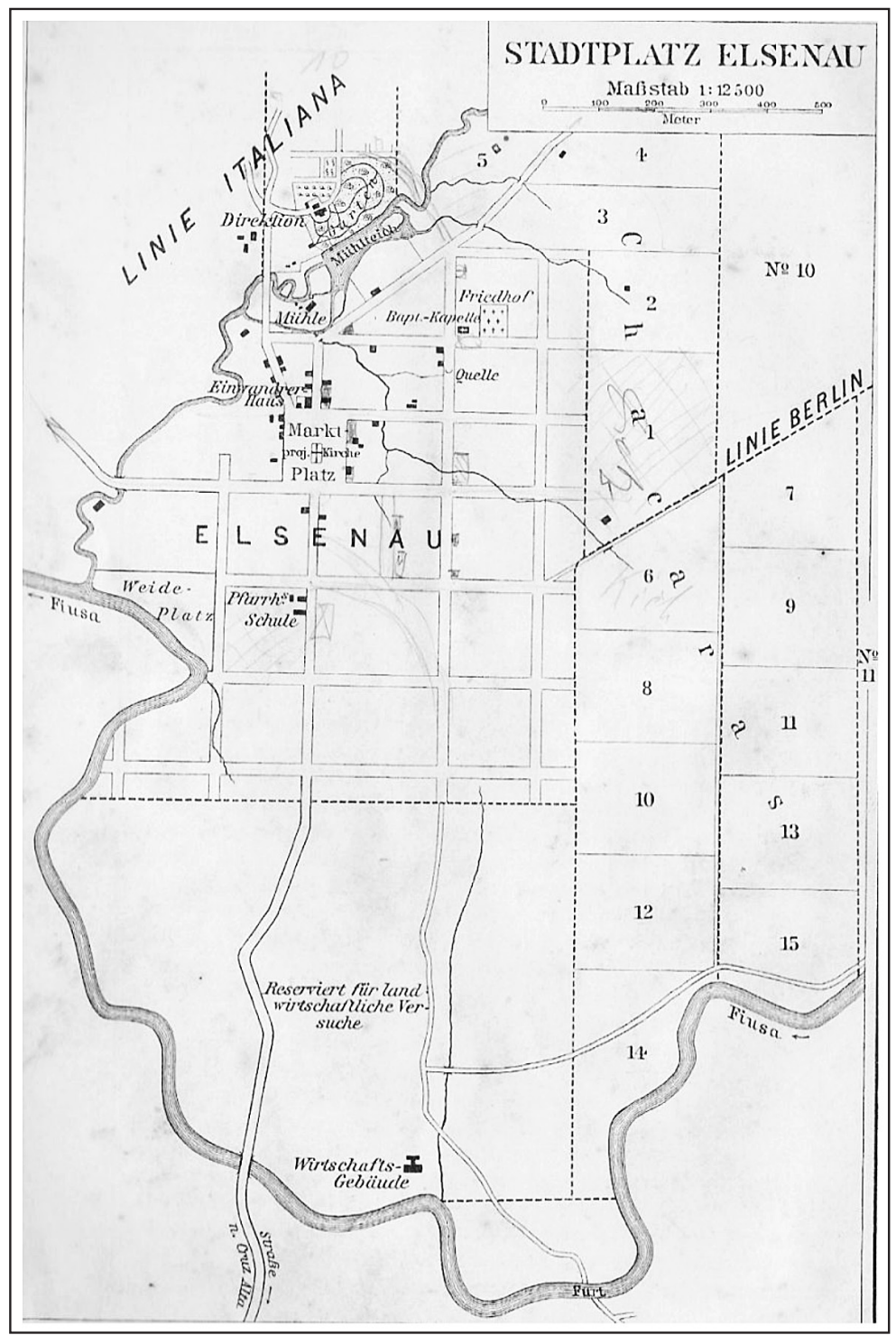

Fonte: MEYER (1906).

$\overline{11}$ Carta. Leipzig, 31/5/1906. Herrmann Meyer a Alfred Bornmüller, Colônia Neu-Württemberg. Pasta Cartas Herrmann Meyer a Alfred Bornmüller, Caixa 43, MAHP. 
Figura 3 - Planta definitiva do Stadtplatz de Neu-Württemberg ${ }^{12}$

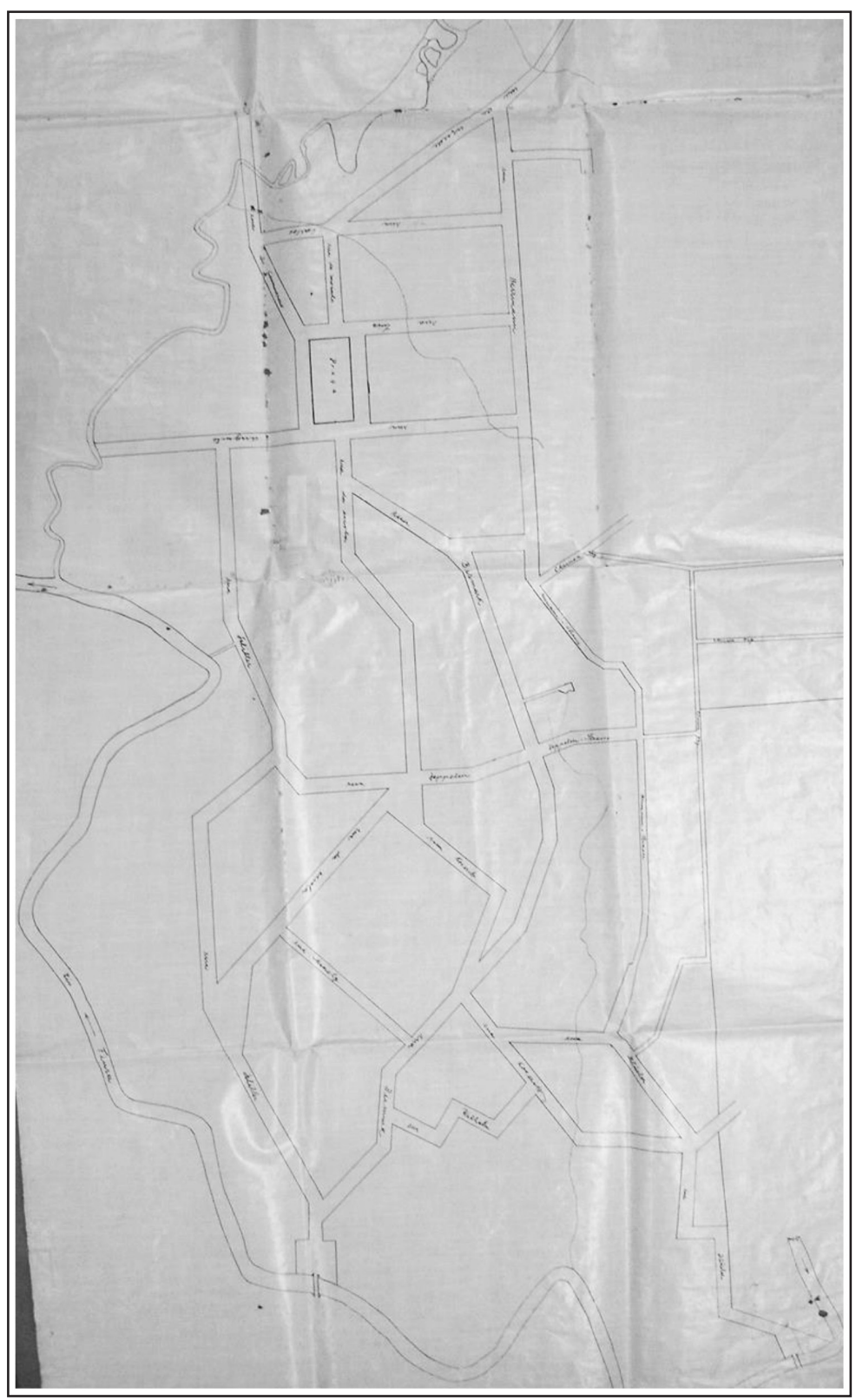

Fonte: Pasta Stadtplatz Elsenau, Caixa 15, MAHP.

$\overline{12}$ Não há identificação da data. 
O núcleo central começou a se formar em torno da Casa do Imigrante e da Praça do Mercado. Com as alterações no traçado urbano, a Praça da Igreja foi suprimida, e a igreja, que originalmente seria construída no terreno 12 da quadra 27 (Figura 1), foi projetada para ser edificada na Praça do Mercado. Subentende-se que a planta mencionava a igreja protestante luterana, que acabou sendo construída ao lado da escola, conforme a primeira planta, na quadra 14. Já na praça central, permaneceu a igreja católica, e, na quadra 33, a capela batista e o cemitério.

Talvez relacionado à própria formação de Herrmann Meyer como geógrafo, e à especialização do Instituto Bibliográfico na produção de plantas e mapas, esse tipo de material foi utilizado com mais ênfase na propaganda das colônias, apresentando pelo seu traçado um lugar planejado, ordenado, projetando a ideia de que essa era a essência também da Colonizadora envolvida. Quanto à circulação desse material, além de constarem nos prospectos de propaganda, circulavam de forma isolada, em bem maior número. Por exemplo, em 1902, Meyer remeteu para Horst Hoffmann, em Porto Alegre, "6 brochuras e 150 mapas (Karte) dos 4 suplementos do Brasil" - planta das colônias Xingu e Neu-Württemberg, o mapa do Rio Grande do Sul, com a localização de seu complexo colonial e um da região do complexo. Informou ainda que de cada planta/mapa havia feito 300 cópias, e a planta do Stadtplatz Elsenau já havia mandado reproduzir e em breve estaria enviando as cópias ${ }^{13}$.

Neu-Württemberg, então, consistiu-se na colônia em que prevaleceu, de forma mais visível e presente, o perfil de uma colônia alemã e com um projeto de urbanização. Nas demais áreas da empresa, não se procurou implementar uma colônia nos mesmos moldes de Neu-Württemberg, muito pelo contrário, prevaleceu a pura e simples venda de lotes de terras, permanecendo as nominações já adotadas ou de uso corrente no momento da aquisição das terras. Foi o caso da posse Boi Preto, cuja área não foi colonizada, em Palmeira, e da posse ou colônia Castilhos, localizada entre os arroios Monjolo e Anta, e dividida pelo Arroio Felisberta, em Júlio de Castilhos ${ }^{14}$, comprada à família Castilhos. A área foi fracionada em lotes coloniais, terceirizada a sua venda e formando a Linha Felisberta.

Finalmente, a última área colonizada pela Empresa de Colonização Dr. Herrmann Meyer, já na segunda metade da década de 1920, foi a colônia Guarita/Fortaleza, formada por duas grandes posses contíguas, uma localizada no lugar denominado Guarita, e a outra, no lugar chamado Fortaleza, delimitadas pelos respectivos rios Guarita e Fortaleza, motivo pelo qual as duas referências eram utilizadas indistintamente pela administração da empresa. No momento da colonização, oficialmente, passou a ser chamada de Colônia Fortaleza, atual Erval Seco. Seguindo os modelos urbanos da época, bem como as determinações governamentais ${ }^{15}$, o engenheiro responsável pelos trabalhos de medição, Alfred Closs, de Carazinho, definiu uma sede maior, Erval Seco, designação confirmada por

\footnotetext{
${ }^{13}$ Carta privada. Leipzig, 17/2/1902. Herrmann Meyer a Horst Hoffmann, Porto Alegre. Pasta Carta Herrmann Meyer a Horst Hoffmann, Caixa 42, MAHP.

${ }^{14}$ O município de Júlio de Castilhos foi criado em 1891, com o nome de Vila Rica. Até então era distrito do município de São Martinho, desmembrado em 1876 de Cruz Alta.

15 A partir de 1919, a Diretoria de Terras e Colonização passou a defender a delimitação e organização de áreas urbanas nas colônias como algo obrigatório, bem como a localização de uma colônia próxima a outra e de centros urbanos. Isso prevendo que essas colônias virariam municípios (Relatório da Diretora de Terras e Colonização, 1919). Nas colônias de Meyer, com exceção de Xingu, foi delimitada de imediato uma área urbana.
} 
Eduard Hempe porque era o nome pelo qual o lugar era conhecido há muito tempo - e uma sede secundária, Italiana, e, adjacentes a elas, as chácaras. Como naquele momento o interesse de Hermann Faulhaber concentrava-se na colônia Porto Feliz, em Santa Catarina, e Herrmann Meyer estava mais interessado em se desfazer dessa área, não houve uma preocupação maior com a composição étnica ou confessional da colônia. Assim, dentre os compradores, além de migrantes de origem alemã da colônia Neu-Württemberg e de outras regiões coloniais, encontrava-se um significativo número de colonos italianos e um elevado número de luso-brasileiros. Essa despreocupação fica evidente também na designação das linhas coloniais, mantendo os nomes já em uso no local: Linha Barra, Caçador, Capivara, das Cannas, Fortaleza, Guarita, Italiana, Palmeira, Vitor, 3 de Maio. Dentro das prerrogativas de uma colônia particular, a Colonizadora Meyer cedeu um terreno para escola, igrejas e subprefeitura na sede Erval Seco, onde subvencionou, por um curto prazo, o professor da escola ali instalada. Já na década de 1940, a denominação Erval Seco passou a predominar e denominar toda a área, e, posteriormente, por ocasião da constituição como município, prevaleceu ${ }^{16}$.

A colonização de áreas previamente já ocupadas abriu um campo de disputas pelo poder de nomear, ou renomear os lugares. Onde não enfrentou resistência, tal tentativa obteve sucesso, nos demais casos, nomes duplos concorreram no uso formal e cotidiano, até um se afirmar. No entendimento de Certeau (2007, p. 189), o que mais impressiona "é o fato de os lugares vividos serem como presenças de ausências. O que se mostra designa aquilo que não é mais: 'aqui vocês veem, aqui havia...', mas isto não se vê mais. Os demonstrativos dizem do visível suas invisíveis identidades".

\section{Referências}

ARAÚJO, João Raimundo de. Nova Friburgo: A Construção do Mito da Suíça Brasileira (1910-1960). Tese (Doutorado) - Programa de Pós-Graduação em História, Universidade Federal Fluminense, Niterói, 2003.

BYTSENKO, Anastassia. Imigração da Rússia para o Brasil no início do século XX. Visões do Paraíso e do Inferno. 2006. Dissertação (Mestrado) - Programa de Pós-Graduação de Literatura e Cultura Russa, Universidade de São Paulo, São Paulo, 2006.

CERTEAU, Michel de. A invenção do cotidiano: 1. Artes de fazer. 13. ed. Petrópolis: Vozes, 2007.

CONSTANTINO, Núncia Santoro de. Imigrantes italianos: partir, transitar, chegar (1889-1930). In: BOEIRA, Nelson; GOLIN, Tau (Coord.). República Velha (1889-1930). v. 3, t. 1. Passo Fundo: Méritos, 2007. p. 395-418.

DREHER, Martin N. Os 180 anos da imigração alemã. In: ARENDT, Isabel Cristina; WITT, Marcos Antônio (Orgs.). História, cultura e memória: 180 anos de imigração alemã. São Leopoldo: Oikos, 2005.

\footnotetext{
${ }^{16}$ A colônia Fortaleza era o $7^{\circ}$ distrito de Palmeira. Com a emancipação de Seberi, em 1959, passou a integrar o território deste município. Foi emancipado sob o nome de Erval Seco, em 1963, desmembrando-se, em 1992, o município de Dois Irmãos Missões.
} 
MEYER, Herrmann. Ackerbaukolonien. Neu-Württemberg und Xingu in Rio Grande do Sul (Südbrasilien). Leipzig: Bibligraphischen Institut, 1906.

. Meine Reise nach den deutschen Kolonien in RS. 1898-1899.

Gedruckt als "Reisebrief" für seine Freunde. Leipzig: Carl Meyers Graphisches Institut, 1899.

NEUMANN, Rosane Marcia. Uma Alemanha em miniatura: o projeto de imigração e colonização étnico particular da Colonizadora Meyer no noroeste do Rio Grande do Sul (1897-1932). 2 v. Tese (Doutorado) - Programa de Pós-Graduação em

História, Pontifícia Universidade Católica do Rio Grande do Sul, Porto Alegre, 2009.

RELATÓRIO DA DIRETORA DE TERRAS E COLONIZAÇÃO apresentado pelo Dr. Ildefonso Soares Pinto ao Dr. A. A. Borges de Medeiros, em 27 de agosto de 1919. Porto Alegre: Oficinas Gráficas d'“A Federação”, 1919.

SOUSA, Fabio Gutemberg Ramos Bezerra de. Cartografias e imagens da cidade:

Campina Grande - 1920-1945. 2001. Tese (Doutorado) - Universidade de Campinas, Campinas, 2001

WEBER, Max. Conceito e categorias da cidade. In: VELHO, Otávio Guilherme (Org.). O fenômeno urbano. 4. ed. Rio de Janeiro: Zahar, 1979. p. 68-89.

WEIMER, Günter. Arquitetura popular da imigração alemã. 2. ed. Porto Alegre: UFRGS, 2005.

WIRTH, Louis. O urbanismo como modo de vida. In: VELHO, Otávio Guilherme (Org.). O fenômeno urbano. 4. ed. Rio de Janeiro: Zahar, 1979. p. 90-113. 